\title{
Antifungal Susceptibility Profile of Candida Isolates from Bloodstream Infections in Hospitalised Patients at Tertiary Care Hospital
}

\author{
Pallavi S. Tatte* and Pramod R. Bhise \\ Department of Microbiology, Dr. Panjabrao Deshmukh Memorial Medical College, \\ Amravati, Maharashtra, India \\ *Corresponding author
}

\section{A B S T R A C T}

\section{Keywords}

Candida albicans, Non albicans Candida, Candidemia, Antifungal susceptibility

Article Info

Accepted:

10 September 2018 Available Online: 10 October 2018
During recent decades, there has been a change in the epidemiology of Candida infections, characterized by progressive shift from predominance of Candida albicans to non albicans Candida. The aim of present study to isolate and identify the different Candida spp. from BSIs and evaluate its antifungal susceptibility pattern the present study was conducted in department of Microbiology for a period of one year (January - December 2016) which included, 48 Candida spp. isolated from BSIs. The speciation was done by conventional methods. Antifungal susceptibility testing of the isolates was performed by Minimum Inhibitory Concentration test. A total of 48 isolates of Candida species were recovered from blood samples of 454 patients [Candida albicans (31.25\%), C. tropicalis (25\%), C. glabrata (20.84\%), C. krusei (16.66\%), C. parapsilosis $(4.17 \%)$, C. guilliermondii $(2.08 \%)]$. Isolation of NAC spp. was significantly higher than Candida albicans. Fluconazole and Amphotericin B resistance was seen in $18(37.5 \%)$ and 3(6.25\%) of the isolates respectively. Candidemia is emerging as a significant problem in hospitalized patients. Non albicans candida is major cause of candidemia as found in our study.

\section{Introduction}

The frequency of invasive, opportunistic mycosis has increased significantly over the past two decades. Candida species account for 8-10\% of all nosocomial blood stream infections (Pfaller et al., 2006). Increased incidence of candidemia is seen in hospitalised patients especially admitted in Intensive care units (ICUs). It is reported as the $4^{\text {th }}$ common cause of blood stream infections (BSIs) in USA, with a mortality rate as high as $30-40 \%$ (Beck-Sague and Jarvis, 1993). This is directly related to the increasing number of patients at risk of serious fungal infections, including patients undergoing blood and marrow transplantations, solid organ transplantation, major gastrointestinal surgery, neoplasia, patients with acquired immunodeficiency syndrome, on immunosuppressive therapy (Gudlaugsson et al., 2003).

Low birth weight, central venous catheter, urinary catheter, mechanical ventilation, premature infants, diabetes, prolonged use of broad spectrum antibodies also several other predisposing factors are responsible for the occurrence of Candidemia in ICUs (Pfaller 
and Diekema, 2007). Recent report suggests a shift in distribution of Candida species from Candida albicans to non albicans candida in cases of candidemiz (Rex et al., 1995).

The prospective antifungal therapy alliance (PATH) study by Pfaller et al., between 2004 and 2008 reported an increased incidence of $54.4 \%$ of non albicans candida (Pfaller et al., 2014). Increased incidence of antifungal drug resistance has major cause of concern in management of Candidemia (Sahni et al., 2005). The aim of present study was to speciate Candida isolates from blood cultures, $\&$ to evaluate the antifungal susceptibility pattern in these isolates will help in early diagnosis \& prompt therapeutic intervention.

\section{Materials and Methods}

This study was carried out in the department of Microbiology, Dr. P.D.M.M. College \& Hospital, Amravati, a tertiary care center in Maharashtra during the period January 2016 to December 2016. Ethical clearance for the study was obtained from the Institutional Ethics Committee.

Blood samples were collected aseptically in Brain Heart Infusion (BHI) broth from suspected cases of Blood stream infections in different wards and ICUs.

The $\mathrm{BHI}$ bottle was incubated at $37^{\circ} \mathrm{C}$ in the laboratory. Subculture was performed after 48 hours and on $7^{\text {th }}$ day before being reported negative. Subculture was performed on Blood agar, MacConkey agar. Colonies of yeast on Blood agar were identified by their smooth creamy coloured appearance and Gram's staining and subcultured on Sabouraud's Dextrose Agar medium. Speciation of Candida was done by assessing Germ tube test, assimilation and fermentation of sugars, Chlamydospore formation on corn meal agar, colony colour on Hichrom Candida agar.
Antifungal susceptibility testing of the isolates was performed by Hicomb MIC test (Himedia Laboratories Mumbai). The antifungal agents used were Amphotericin B (range 0.002-32 $\mathrm{mcg}$ ), Fluconazole (range 0.016-256 mcg), Itraconazole (range 0.002-32 $\mathrm{mcg}$ ), Ketoconazole (range 0.002-32 $\mathrm{mcg}$ ) and Voriconazole (range 0.002-32 mcg).

The suspension of the isolate to be tested was prepared in $0.85 \%$ saline. The turbidity of each suspension was adjusted to $0.5 \mathrm{Mc}$ Farland standard. The suspension was inoculated on agar plates containing RPMI 1640 supplemented with glucose using sterile cotton tipped swab. The antifungal strips were placed on the media and the plates were incubated for $48 \mathrm{~h}$ at $35^{\circ} \mathrm{C}$. The minimum inhibitory concentration (MIC) of each isolate against each antifungal tested was read after 24 and $48 \mathrm{hr}$.

C. albicans ATCC 90028 and C. parapsilosis ATCC 22019 were used for the purpose of quality control. The antifungal susceptibility of the isolates was reported as sensitive (S), dose dependent-susceptible (DDS) and resistant (R). For Fluconazole and Itraconazole the results were evaluated as per the interpretive susceptibility criteria recommended by Clinical and Laboratory Standard Institute (CLSI) [formerly known as National Committee for Laboratory Standards (NCCLS)] M27-A2 standard guidelines. (Clinical and Laboratory Standards Institute, 2002) Due to the lack of defined breakpoints for amphotericin B and ketoconazole, arbitrary values based on the studies of other researchers were used (Priscilla et al., 2002).

\section{Results and Discussion}

In the present study, between January to December 2016, out of 454 blood culture samples, Candida spp. were isolated from the blood cultures of 48 patients. Figure 1 shows 
the Age and sex distribution of Candidemia patients. Male predominance was noted in our study $(n=31 / 48) 64.6 \%$. Candidemia was common in below $10 \mathrm{yrs}$ and more than $50 \mathrm{yrs}$ age groups in males than females. In this study predominant isolates were NAC spp. 33 (68.75) and C. albicans was isolated from 15 $(31.25 \%)$ cases (Table 1). Among the NAC species, C. tropicalis, C. glabrata and $C$. krusei were the major isolates (Figure 2).

The most important risk factors associated with candidemia was ICU stay, followed by Neonates, Catheter related infections, Diabetes (Figure 3).

The antifungal susceptibility and resistant pattern of all Candida isolates from blood stream infections was evaluated (Table 2).

A total of $18(37.5 \%)$ isolates were resistant to Fluconazole. Fluconazole resistant was more in $C$. tropicalis followed by $C$. glabrata (Figure 4).

Maximum resistance to Ketoconazole was shown by $C$. albicans followed by $C$. tropicalis and C. glabrata (Figure 5). Itraconazole resistance was more in $\mathrm{C}$. tropicalis (Figure 6). Voriconazole resistant was also noted in $3(6.25 \%)$ and Amphotericin $\mathrm{B}$ resistant was noted in $3(6.25 \%)$ was shown in figure 7 and 8 respectively. Resistant to Amphotericin B and Voriconazole was not noted in $C$. guillermondii and $C$. parapsilosis.

The prevalence of Candida species in BSI has increased worldwide in the last three decades. In our study overall prevalence of Candida species in BSI of ICU patients was found to be $10.57 \%$ in the one year study period.

There are many reports on the prevalence of Candida in BSI from different part of the world. In the United States, a seven yearlong study has reported Candida species to be the $4^{\text {th }}$ most common cause of BSI in hospitals (Wisplinghoff et al., 2004). A 10 year study on the epidemiology of Candidemia in Switzerland found Candida species to be the $7^{\text {th }}$ most common cause of BSI in tertiary care hospital (Marchetti et al., 2004).

Lot of variation in the prevalence and incidence of Candidemia have been reported from India. A study by Verma et al., from SGPGI, Lucknow ranked Candida species as $8^{\text {th }}$ among all isolates causing BSI with incidence rate of $1.61 \%$ (Verma et al., 2003). In a five year study from All India Institute of Medical Sciences (AIIMS), New Delhi, Xess et al., found a prevalence of $6 \%$ for Candida Species in BSI (Xess et al., 2007). Sahni et al., from Maulana Azad Medical College, New Delhi found the incidence rate of Candidemia to be $6.9 \%$ (Sahni et al., 2005).

Another New Delhi based study found that the percentage of Candida species among positive blood culture isolates was $18 \%$ (Kothari and Sagar, 2009). Kumar et al., from South India reported an incidence rate of $5.7 \%$ for Candidemia among children with oncohaematological malignancies. (Kumar et al., 2005) Another study from Rohtak, North India reported an isolation rate of $8.1 \%$ for Candida species from cases of neonatal septicaemia (Goel et al., 2009). A study by Jain et al., during year 2001 showed Candidemia to be present in $6 \%$ of neonates with suspected septicaemia (Jain et al., 2003) and during year 2003 Candida was isolated from a total of 90 neonates i. e. isolation rate $13.6 \%$ where majority of the isolates were non albicans Candida (Jain et al., 2004). Prateek et al., North India reported prevalence of $16 \%$ for Candida species in BSI (Gupta et al., 2015). A Two year study from SCB Medical college, Cuttack M. Bhatt et al., found a prevalence of 9.4\% for Candida sp in BSI (Bhatt et al., 2015) and Giri et al., reported prevalence of 0.65\% (Giri et al., 2013) (Table 3). 
Table.1 Comparison of antifungal susceptibility of $C$. albicans \& non-albicans

\begin{tabular}{|c|c|c|c|c|c|c|}
\hline Isolates & Number $\%$ & \multicolumn{5}{|c|}{ Resistance \% } \\
\hline & $\mathrm{N}=48$ & Fluconazole & Ketoconazole & Voriconazole & Itraconazole & Amphotericin B \\
\hline C. albicans & $\begin{array}{l}15 \\
(31.25 \%)\end{array}$ & $4(26.66 \%)$ & $4(26.66 \%)$ & $1(6.66 \%)$ & $2(13.33 \%)$ & $0(0 \%)$ \\
\hline $\begin{array}{l}\text { Non albicans } \\
\text { Candida }\end{array}$ & $\begin{array}{l}33 \\
(68.75 \%)\end{array}$ & $14(42.42 \%)$ & $10(30.30 \%)$ & $2(6.06 \%)$ & $9(27.27 \%)$ & $3(9.09 \%)$ \\
\hline
\end{tabular}

Table.2 Antifungal resistance pattern of Candida species

\begin{tabular}{|c|c|c|c|c|c|c|}
\hline \multirow[t]{2}{*}{ Candida species } & \multirow{2}{*}{$\begin{array}{l}\text { No. of } \\
\text { cases } \\
(n=48)\end{array}$} & \multicolumn{5}{|c|}{ Resistance \% } \\
\hline & & Fluconazole & Ketoconazole & Voriconazole & Itraconazole & Amphotericin B \\
\hline C.albicans & 15 & $4(26.66 \%)$ & $4(26.66 \%)$ & $1(6.66 \%)$ & $2(13.33 \%)$ & $0(0 \%)$ \\
\hline C. tropicalis & 12 & $5(41.66 \%)$ & $4(33.33 \%)$ & $0(0 \%)$ & $4(33.33 \%)$ & $1(8.33 \%)$ \\
\hline C. glabrata & 10 & $4(40 \%)$ & $3(30 \%)$ & $1(10 \%)$ & $3(30 \%)$ & $1(10 \%)$ \\
\hline C. krusei & 8 & $3(37.5 \%)$ & $2(25 \%)$ & $1(12.5 \%)$ & $1(12.5 \%)$ & $1(12.5 \%)$ \\
\hline C. parapsilosis & 2 & $1(50 \%)$ & $1(50 \%)$ & $0(0 \%)$ & $1(50 \%)$ & $0(0 \%)$ \\
\hline C. guilliermondii & 1 & $1(100 \%)$ & $0(0 \%)$ & $0(0 \%)$ & $0(0 \%)$ & $0(0 \%)$ \\
\hline Total & 48 & $18(37.5 \%)$ & $14(29.16 \%)$ & $3(6.25 \%)$ & $11(22.91 \%)$ & $3(6.25 \%)$ \\
\hline
\end{tabular}

Table.3 Showing Indian studies on Fluconazole, Itraconazole, Voriconazole resistance

\begin{tabular}{|l|l|l|}
\hline Reference & Place of study & $\begin{array}{l}\text { Percentage resistance to } \\
\text { azoles }\end{array}$ \\
\hline Present study, 2017 & Amravati, Maharashtra & $\begin{array}{l}\text { Fluconazole (37.5) } \\
\text { Itraconazole (22.91) } \\
\text { Voriconazole (6.25) }\end{array}$ \\
\hline Kothari et al., 2008 & New Delhi & $\begin{array}{l}\text { Fluconazole (36) } \\
\text { Itraconazole (24) } \\
\text { Voriconazole (56) }\end{array}$ \\
\hline Xess et al., 2007 & New Delhi & Fluconazole (11.7) \\
\hline Gupta et al.,2001 & Fluconazole (37.5) \\
\hline Capoor et al., 2005 & New Delhi & $\begin{array}{l}\text { Fluconazole (4.9) } \\
\text { Itraconazole (3.9) }\end{array}$ \\
\hline Kumar et al., 2005 & Fluconazole (17.2) \\
\hline Goel et al., 2009 & Chennai & Fluconazole (4.5) \\
\hline Adlhikary et al., 2011 & Rohtak & Fluconazole (25) \\
\hline Kaur R et al., 2014 & Banglore & Fluconazole (58.25) \\
\hline
\end{tabular}


Fig.1 Age and sex distribution of Candidemia patient

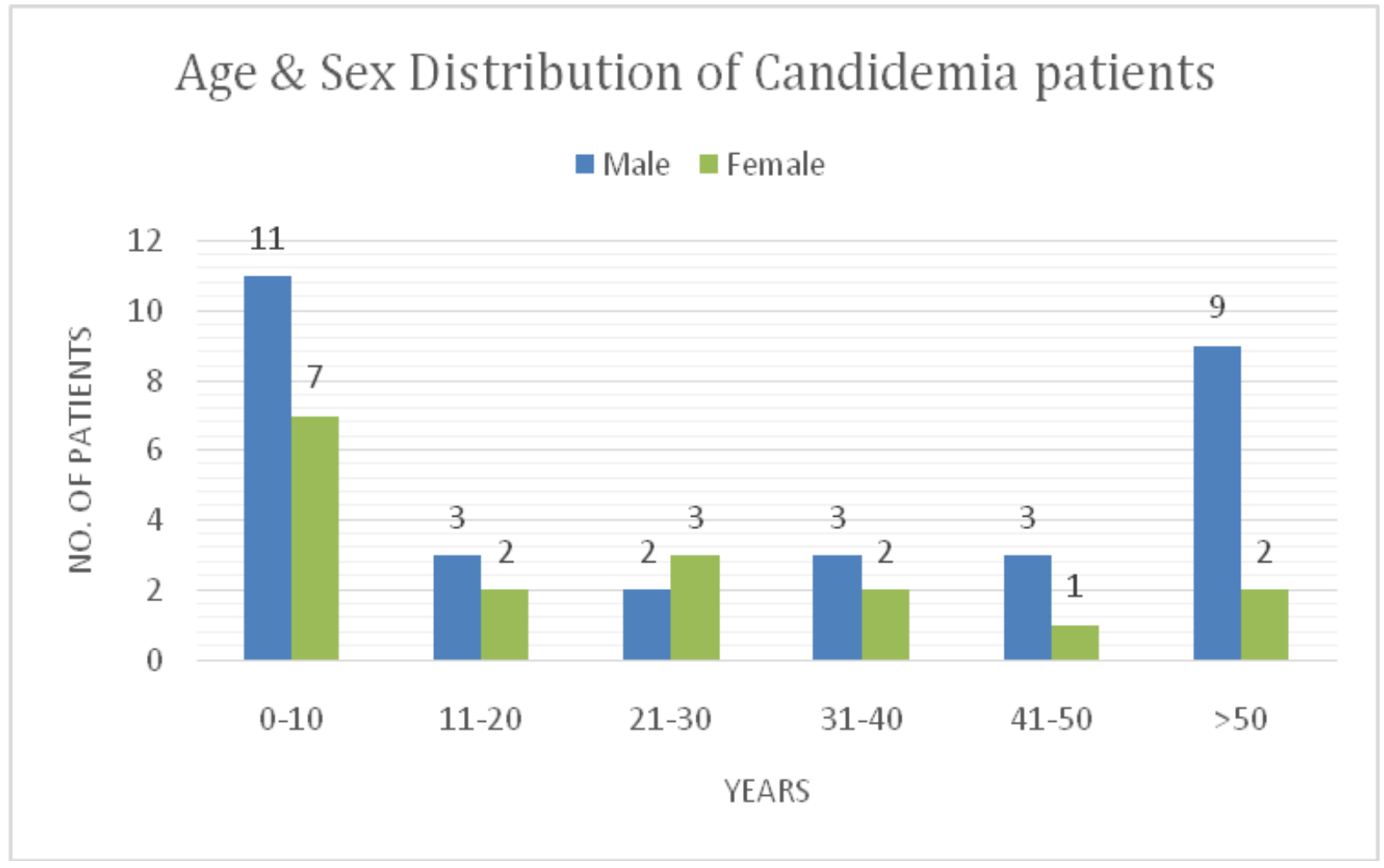

Fig.2 Distribution of Candida species isolated from Candidemia patients

\section{Species-wise distribution of Candida Isolates}

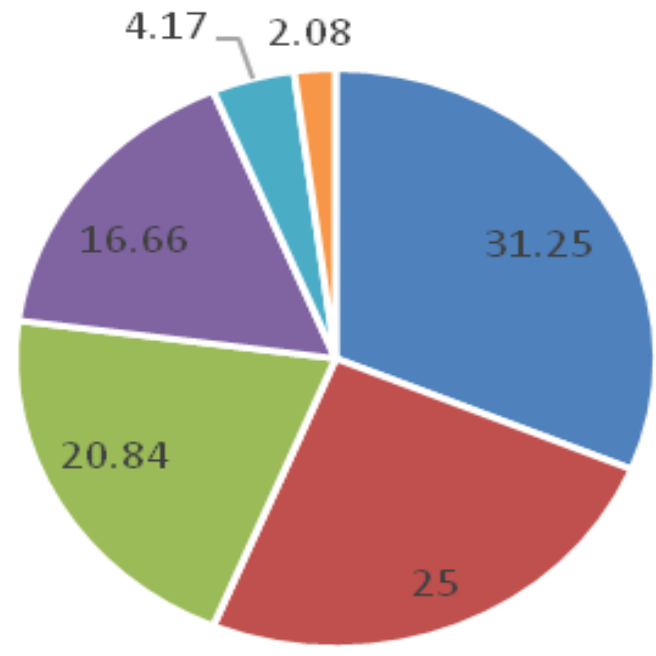

- C. albicans

- C. tropicalis

- C. glabrata

- C. krusei

- C. parapsilosis

- C. guilliermondii 
Fig.3 Risk factors predisposing Candidemia

\section{Risk factors predisposing Candidemia}

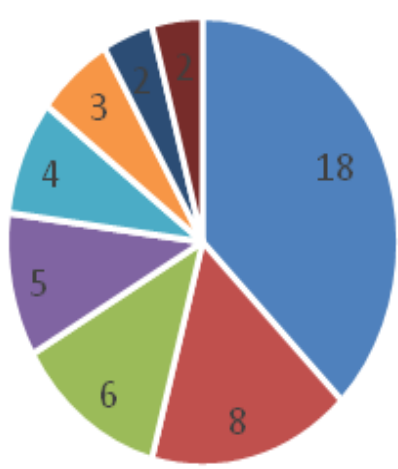

- ICU stay

- Neonate

- Urinary catheter

- Diabetes mellitus

- Prolong Antibiotic = HIV infection

- Ventilator

- Central line

Fig.4 Antifungal profile of Candida albicans \& NAC Spp (Fluconazole)

\section{Antifungal profile of C. albicans \& NAC \\ (Fluconazole)}

10

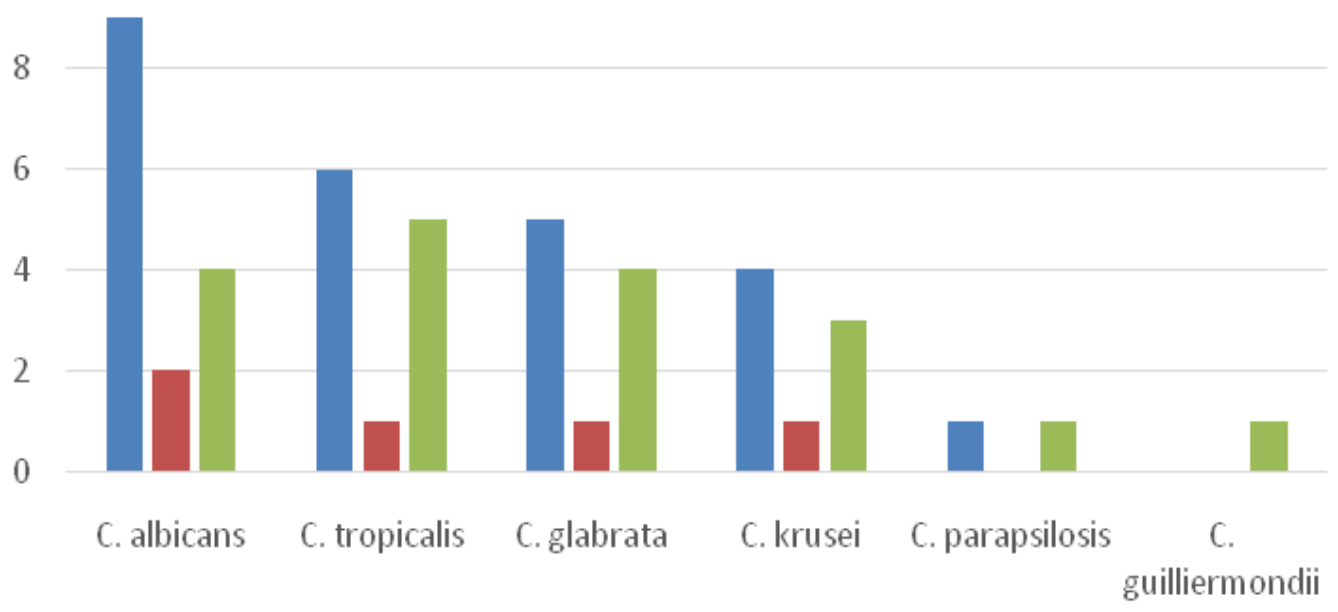

$\square \mathrm{S} \square \mathrm{DDS} \backsim \mathrm{R}$ 
Fig.5 Antifungal profile of Candida albicans \& NAC Spp (Ketoconazole)

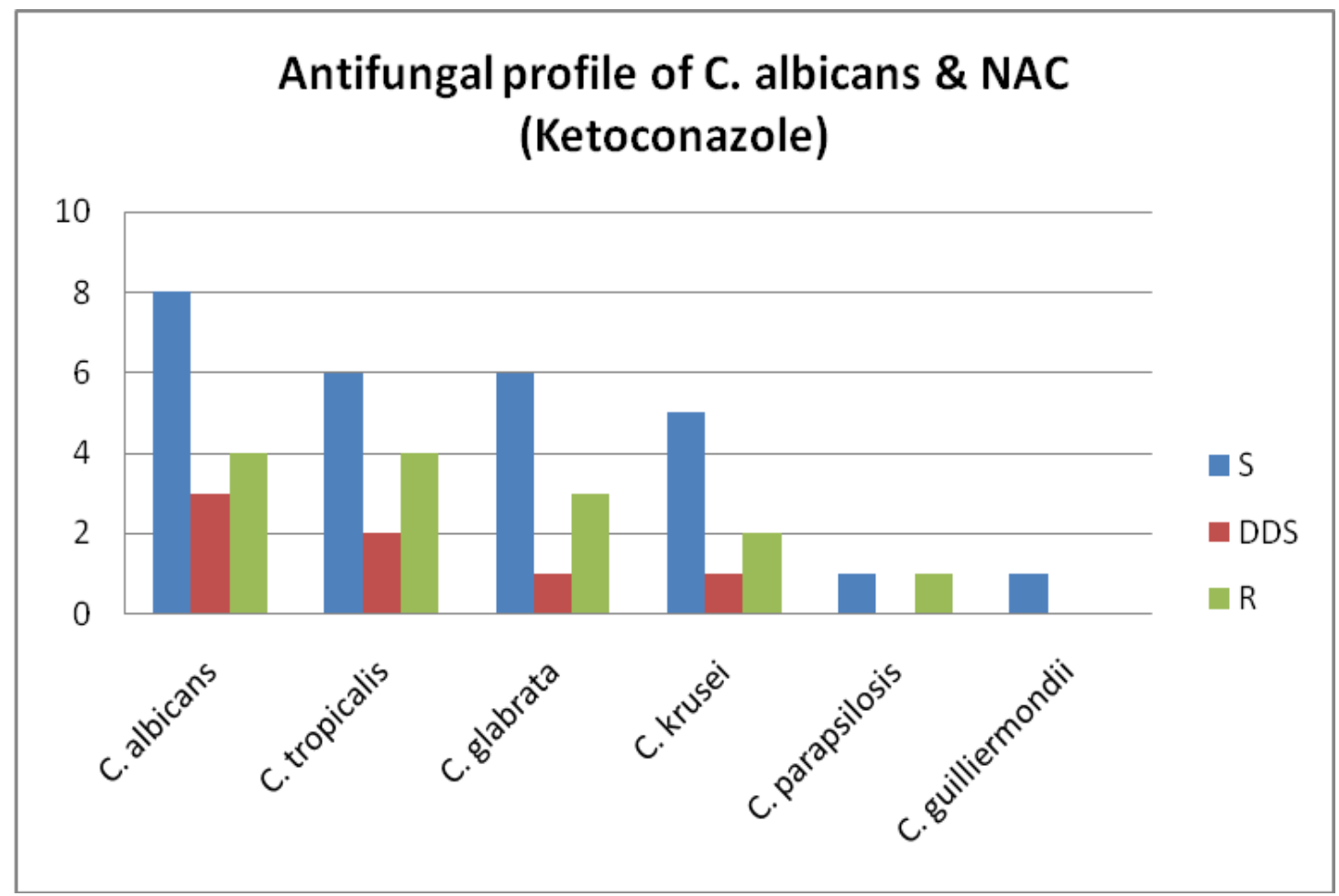

Fig.6 Antifungal profile of Candida albicans \& NAC Spp (Itraconazole)

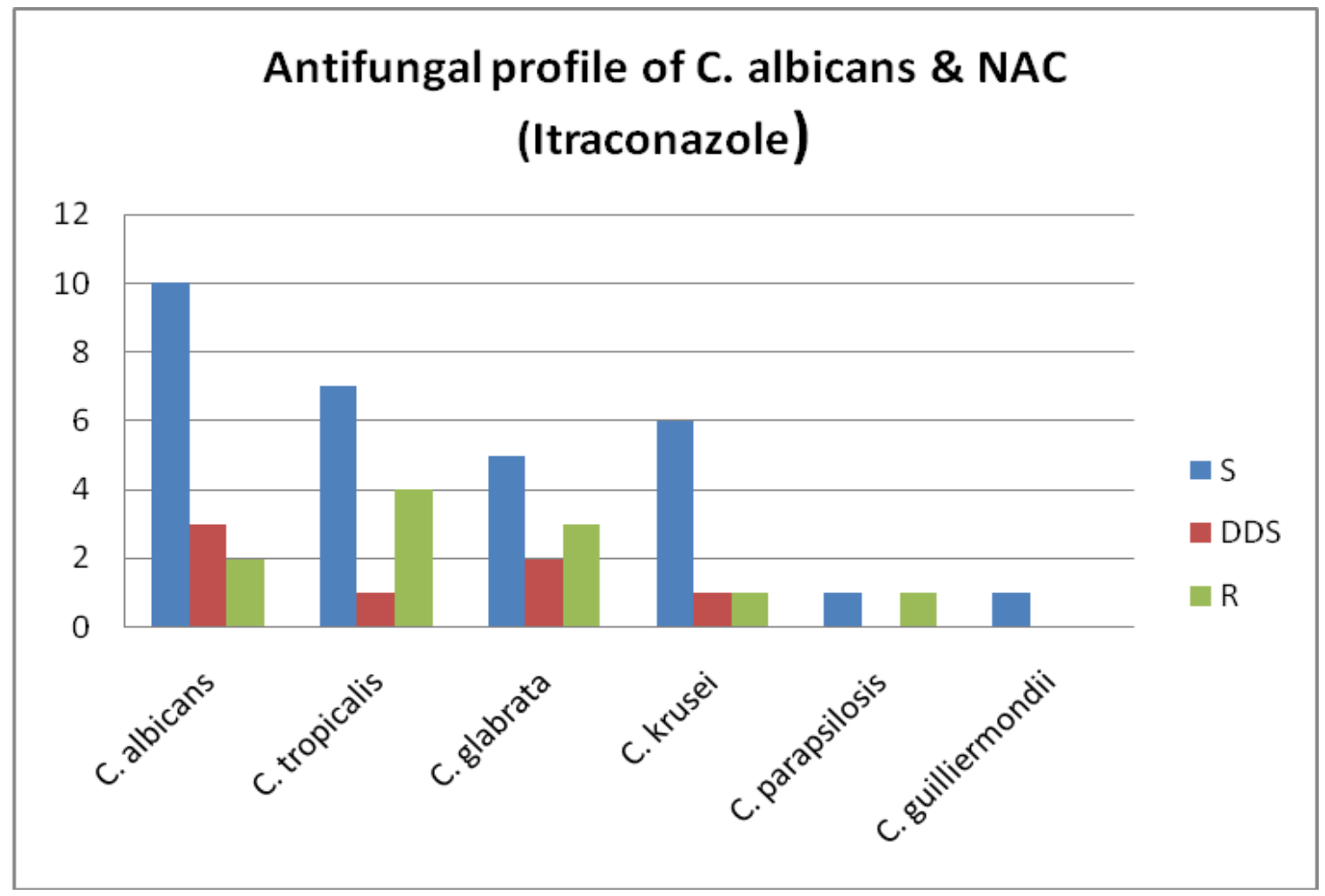


Fig.7 Antifungal profile of Candida albicans \& NAC Spp (Voriconazole)

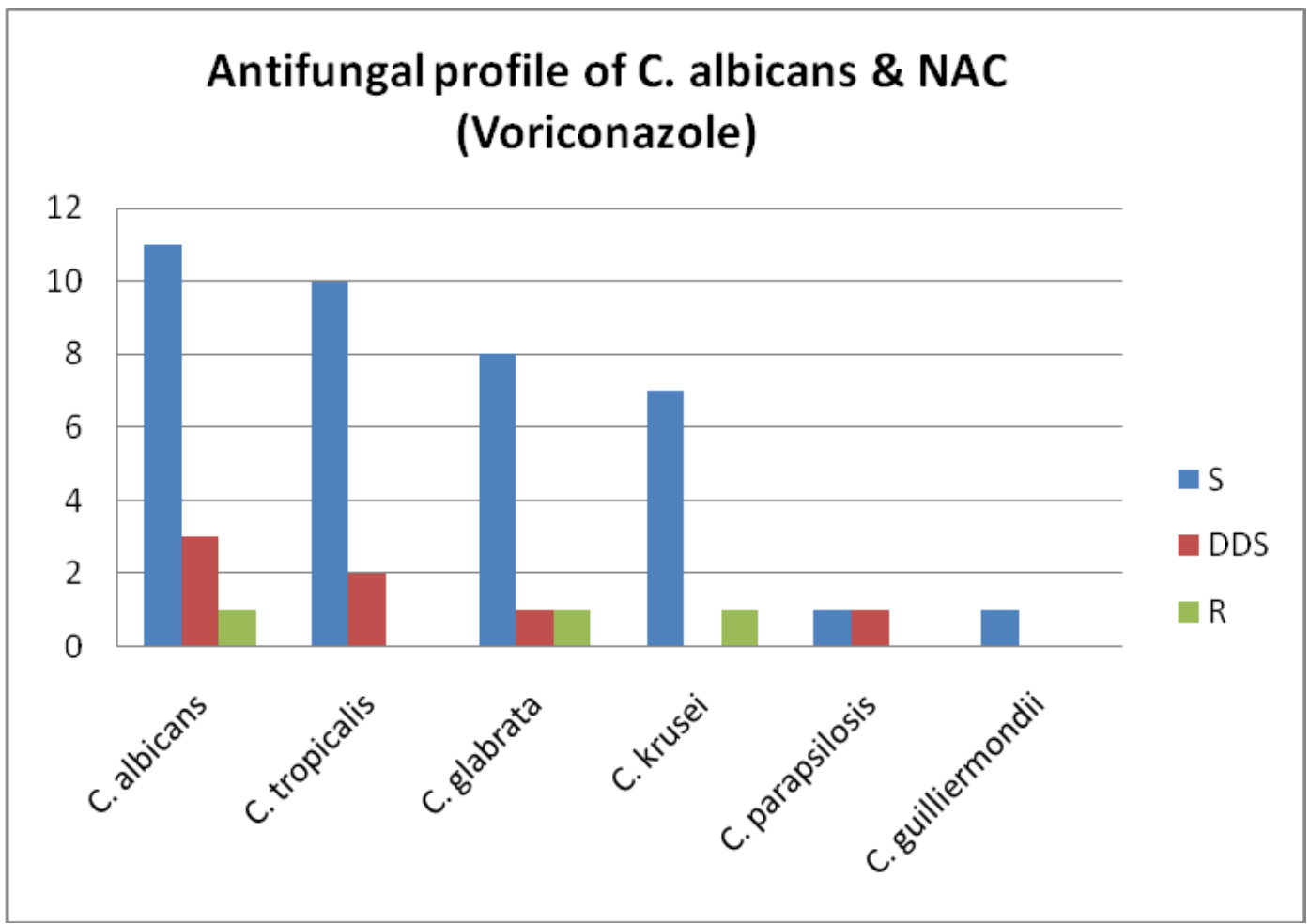

Fig.8 Antifungal profile of Candida albicans \& NAC Spp (Amphotericin B)

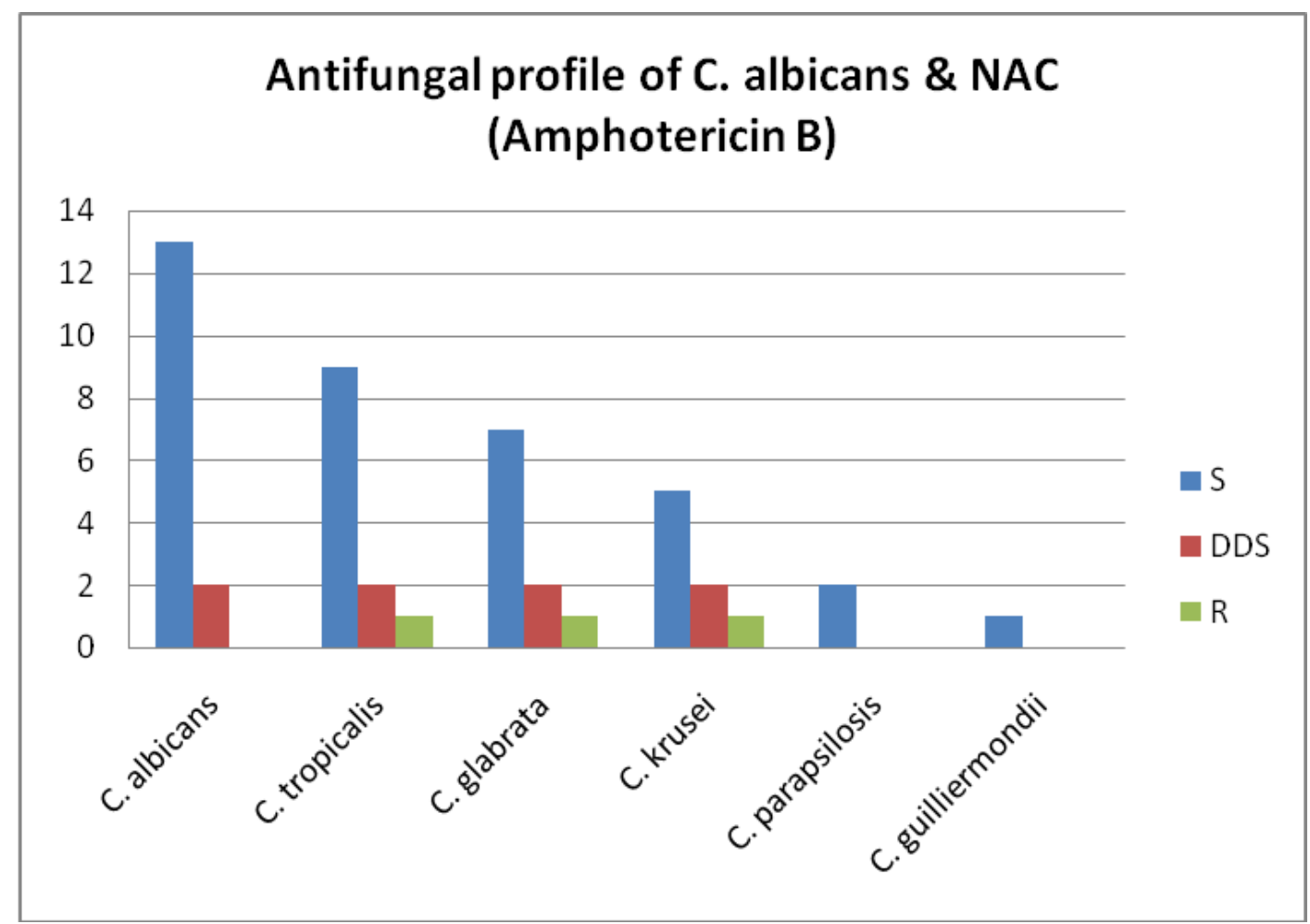


The incidence of BSI caused by NAC spp. was higher than $C$. albicans at our hospital. Among the NAC spp. C. tropicalis followed by $C$. glabrata and $C$. krusei pre-dominantely caused BSI. A number of international surveillance programs like ARTEMIS Antifungal Surveillance study conducted in 127 heath care centres in 39 countries have documented increased prevalence of NAC species like $C$. tropicalis and C. parapsilosis (Pfaller et al., 2005).

C. tropicalis was found to be the most common isolates from Candidemia pts by (Shivprakash et al., 2007) (35.6\%) and (Adhikary et al., 2011) (39.7\%) respectively. Xess et al., from AIIMS, New Delhi also found $C$. tropicalis to be the most common species of Candida in blood isolates $(35.3 \%)$ (Xess et al., 2007).

Factors like increased use of antifungal drugs, use of broad spectrum antibiotics, long term use of catheters, and increased in number of immunocompromised patients contributes to the emergence of $C$. tropicalis (Kothavade et al., 2010), previous studies by Chakraborti et al., (2009), Singh et al., (2011) and Tak et al., (2014) are in agreement with our study.

C. glabrata was the second most common NAC spp isolated in the present study. Trick et al., also Chander et al., reported a considerable increase in the incidence rate of isolation of $C$. glabrata from BSI pts (Trick et al., 2002; Chander et al., 2013). C. glabrata infections are common in immunocompromised hosts and diabetes mellitus patients. It is also associated with high mortality rates in at risk hospitalised and immunocompromised patients (Hitchcock et al., 1993).

In recent years, emphasis has been laid on other risk factors like long period of hospitalization in ICUs especially surgical
ICUs (Blumberg et al., 2001), also long term antibiotic therapy (Chowta et al., 2007). C. parapsilosis has been particularly implicated to cause intravascular catheter related infections in neonates and pediatric age group (Karlowicz et al., 2000).

The average central venous catheter related blood stream infections rate was 9.26 per 1000 catheter days ranging from 8.64 per 1000 catheter days in PICU to maximum rate of 27.02 per 1000 catheter days in NICU (Chopdekar et al., 2011).

Candiduria has been found to be a risk factor for candidemia and can be indicator of impending sepsis with Candida species in patients admitted to hospitals, especially those in ICUs (Singh et al., 2011; Chander et al., 2013).

In India, a study by Singh et al., reported that the most common risk factor was presence of urinary catheter $(63.2 \%)$, mechanical ventilation $(63.2 \%)$, peritoneal dialysis $(63.2 \%)$ followed by central line insertion $(47.4 \%)$, diabetes mellitus $(26.3 \%)$ and use of corticosteroids $(21.1 \%)$ of patients with fungal colonization of ICU patients (Singh $e t$ al., 2011).

National nosocomial infection surveillance system of the center for disease control and prevention, Atlanta, USA, reports a CRBSI rate of 5.8 per 1000 catheter days (NNIS, 1999).

A study by Kaur et al., patients with $C$. albicans colonization had risk factors of duration of stay > 1 week in ICU $(36.8 \%)$ and immunosuppressant (31.6\%), and patients with NAC colonization had risk factors of multiple organ system involvement (35.5\%), indwelling devices (96.8\%), prolonged antibiotic therapy (77.4\%) duration of stay > 1 week (45.2\%), use of immunosuppressant 
(38.7\%), and diabetes mellitus (35.5\%) which were significantly higher (Kaur et al., 2016).

A study by Fridkin and Jarvis, frequently identified risk factors for fungaemia in hospitalised patients mainly antimicrobial agents, indwelling catheters (CVCs), ICU stay, Hemodialysis, Neutropenia, Hematological/solid organ malignancy (Fridkin and Jarvis, 1996).

However, there are few studies from different parts of the country which give some idea regarding the epidemiology of antifungal resistance among candidemia isolates (Giri and Kindo, 2012).

In the present study, resistant to amphotericin $\mathrm{B}$ was noted in 3 isolates $(6.25 \%)$. There are very few reports of amphotericin B resistance in Candida isolates from cases of Candidemia in India (Adhikary and Joshi, 2011). Though only $5.8 \%$ isolates of NAC spp. were resistant to amphotericin $\mathrm{B}$, the high frequency of renal toxicity and several other adverse effects limits its use (Deorukhkar and Saini, 2013; Logu et al., 2005).

C. parapsilosis was identified as the most common fungal species in neonates in earlier reports, which is in contrast to our observation. C. tropicalis is virulent and is the second leading cause of Candidemia in adults, but is quite infrequent among neonates. Over all, resistance to fluconazole and amphotericin B was $31.7 \%$ and $13.4 \%$ respectively (Basu et al., 2017). A study by Kaur et al., 60 Candida isolates (58.25 \%) showed resistant to fluconazole while 7 (6.7 $\%)$ isolates showed resistance to amphotericin B (Kaur et al., 2014).

Candidemia in hospitalized patients especially in ICU patients is emerging as a significant problem worldwide. The change in epidemiology and pattern of antifungal susceptibility of Candida infection has made identification of aetiological agent compulsory along with its antifungal susceptibility. Various risk factors have attributed to this increase in Candidemia in the hospital settings. The increase in resistance to antifungal agents among Candida isolates has resulted in increased mortality and morbidity. Prevention of risk factors in Candidemia patients with early removal of central line, timely fungal culture, Candida speciation and antifungal susceptibility are necessary for appropriate treatment and better outcome.

\section{References}

Adhikary R, and Joshi S. Species distribution and antifungal susceptibility of candidemia at a multi super specialty centre in Southern India. Indian J Med Microbiol 2011; 29:309-11.

Basu S, Kumar R, Tilak R, Kumar A. Candida blood stream infection in neonates: Experience from A Tertiary Care Teaching Hospital of Central India. Indian Pediatrics 2017; Jul 15; 54(7): 556-559.

Beck-Sague CM, and Jarvis WR. National Nosocomial Infection Surveillance system. Secular trends in the epidemiology of nosocomial fungal infections in the United States, 19801990. J Infect Dis 1993; 167: 1247-5.

Bhatt M, Sarangi G, Paty BP, Mohapatra D, Chayani N, Mahapatra A, Das P, Sahoo D. Biofilm as a virulence marker in Candida species in nosocomial blood stream infection and its correlation with antifungal resistance. Ind. J. Med. Microbiol. 2015 vol.33, supplement 1, S 112-14.

Blumberg HM, Jarvis WR, Soucie JM, Edwards JE, Patterson JE, Pfaller MA, et al., Risk factors for candidal 
bloodstream infections in surgical intensive care unit patients: The NEMIS prospective multicenter study. The National epidemiology of mycosis survey. Clin Infect Dis 2001; 33:17786.

Chakrabarti A, Chatterjee S.S, Rao K.L., Zameer M.M., Shivaprakash M.R., Singhi S, et al., Recent experience with fungaemia: change in species distribution and azole resistancenScand J Infect Dis, 41 (2009), pp. 275-284.

Chander J, Singla N, Sidhu SK, Gombar S. Epidemiology of Candida blood stream infections: experience of a tertiary care centre in North India; J Infect Dev Ctries, (2013), 7 (9) pp. 670-675.

Chopdekar K, Chande C, Chavan S, Veer P, Wabale V, Vishwakarma K, Joshi A. Central venous catheter -related blood stream infection rate in critical care units in a tertiary care teaching hospital Mumbai. IJMM 2011; 29 (2):169-71.

Chowta MN, Adhikari P, Rajeev A, Shenoy AK. Study of risk factors and prevalence of invasive candidiasis in a tertiary care hospital. Indian J Crit Care Med 2007; 11:67-73.

Clinical and Laboratory Standards Institute: 2002. Reference method for broth dilution antifungal susceptibility testing of yeasts: approved standard, 2nd ed, M27-A2.Clinical and Laboratory Standards Institute, Wayne PA.

Deorukhkar S, and Saini S. Non albicans Candida species: its isolation pattern, species distribution, virulence factors, and antifungal susceptibility profile. Int J. Med Sci Public Health 2013; 2: 533 538.

Fridkin and Jarvis, epidemiology of nosocomial fungal infections. Clin. Microbiol Rev. 1996, vol. 9; 502-505.

Giri S, and Kindo AJ. A review of Candida species causing blood stream infections.
Ind J Med Microbiol 201230 (3): 2708.

Giri S, Kindo AJ, Kalyani J. Candidemia in Intensive care unit patients: A one year study from a tertiary care centre in South India. J Postgrad Med 2013, 59 (3), 190-195.

Goel N, Ranjan PK, Agarwal R, Chaudhary U, Sanjeev N. Emergence of nonalbicans Candida in neonatal septicemia and antifungal susceptibility: Experience from tertiary care centre. J Lab Physicians 2009; 1:53-55.

Gudlaugsson O, Gillespie S, Lee K, Vande Berg J, $\mathrm{Hu} \mathrm{J}$, Messer $\mathrm{S}$ et al., Attributable mortality of nosocomial candidemia, revisited. Clin Infect Dis 2003; 37: 1172-7.

Gupta P, Prateek S, Chatterjee, B, Kotwal A, Singh AK, Mittal G. Prevalence of candidemia in ICU patients in a tertiary care hospital in North India. Int.J.Curr.Microbiol.App.Sci 2015; 4 (6): 566-575.

Hitchcock CA, Pye GW, Troke PF, Johnson EM, Warnock DW. Fluconazole resistance in Candida glabrata. Antimicrob. Agents Chemother 1993; 37:1962-1965.

Jain A, Agarwal J, Bansal S, Malik GK. Trends in neonatal septicemia: Emergence of Non-albicans Candida. Indian Pediatrics 2004; 41: 712-715.

Jain A, Roy I, Gupta MK, Kumar M, Agarwal SK.Prevalence of extended spectrum blactamase producing Gram negative bacteria in septicemic neonates in a tertiary care hospital. J Med Microbiol 2003; 52: 421-425.

Karlowicz MG, Hashimoto LN, Kelly RE Jr, Buescher ES. Should central venous catheters be removed as soon as candidemia is detected in neonates? Pediatrics 2000; 106:e63.

Kaur R, Dhakad MS, Goyal R, Kumar R. Emergence of non-albicans Candida 
species and anti-fungal resistance in intensive care unit patients. Asian Pacific Journal of tropical Biomedicine, 2016, 6 (5), 455-460.

Kaur R, Goyal R, Dhakad MS, Bhalla P, Kumar R. Epidemiology and virulence determinants including biofilm profile of Candida infections in an ICU in a tertiary hospital in India. J Mycol 2014. http://dx.doi.org/10.1155/2014/303491

Kothari A, and Sagar V. Epidemiology of Candida Bloodstream Infection in a Tertiary Care Institute in India. Indian J Med Microbiol 2009; 27:171-172.

Kothavade RJ, Kura MM, Valand AG, Panthaki MH. Candida tropicalis: Its prevalence, pathogenicity and increasing resistance to fl uconazole. J Med Microbiol 2010; 59:873-80.

Kumar CP, Sundarajan T, Menon T, Venkatadesikalu M. Candidiosis in children with onco-hematological studies in Chennai, South India. Jpn J Infect Dis 2005; 58:218-221.

Logu AD, Manuela S, Cardia MC, Borgna R, Sanna C, Saddi B, Elias M. In-vitro activity of 2-cyclohexylidenhydrazo-4phenyl-thiazolecompared with those of amphotericin B andfluconazole against clinical isolates of Candida spp. and fluconazole-resistant Candida albicans. J Antimicrob Chemother 2005; 55: 692698.

Marchetti O, Bille J, Fluckiger U, Eggimann $\mathrm{P}$, Ruef C, Garbino J, et al., Epidemiology of Candidemia in Swiss Tertiary care Hospitals: secular trends, 1991-2000. Clin Infect Dis 2004; 38: 311-20.

National Nosocomial Infections Surveillance (NNIS) system report, data summary from January 1990-May 1999, issued June 1999. Am J Infect Control 1999; 27; 520-32.

Pfaller MA, and Diekema DJ. Epidemiology of invasive candidiasis: A persistent public health problem. Clin Microbiol Rev 2007; 20:133-63.

Pfaller MA, Andes DR, Diekema DJ, Horn DL, Reboli AC, Rotstein C, et al., Epidemiology and outcomes of invasive candidiasis due to non-albicans species of candida in 2,496 patients. Data from the Prospective Anti-fungal therapy (PATH) Registry 2004-2008. PLos ONE 2014; 9 (7): e 101510.

Pfaller MA, Diekema DJ, Rinaldi MG, Barnes R, Hu B, Veselov AV. Results from the ARTEMIS DISK Global antifungal surveillance study: A 6.5-year analysis of susceptibilities of Candida and other yeasts species to fluconazole and voriconazole by standardized disk diffusion testing. J Clin Microbiol 2005; 43: 5848-5859.

Pfaller MA, Pappas PG, Wingard JR. Invasive fungal pathogens: Current epidemiological trends. Clin Infect Dis 2006; 43: S3-14.

Priscilla LSA, Milan EP, Martinez R, Telles FQ, Ferreira MS, Alcantara AL. Multicenter Brazilian study of oral Candida species isolated from AIDS patients. Mem Inst Oswaldo Cruz 2002; 98: 253-257.

Rex JH, Pfaller MA, Barry AL, et al., Antifungal susceptibility testing from a randomised multicenter trial of fluconazole versus amphotericin B as treatment of nonneutropenic patients with candidemia. Antimicrob Agents Chemother 1995; 39:40-4.

Sahni V, Agarwal SK, Singh NP, Anuradha S, Sikdar S, Wadhwa A. Candidemia-An Under-recognized nosocomial infection in Indian Hospitals. J Assoc Physicians India 2005; 53:607-611.

Shivaprakasha S, Radhakrishnan K, Karim P. Candida spp. other than Candida albicans: A major cause of fungaemia in a tertiary care centre. Indian $\mathbf{J}$ Med $2007 ; 25: 405-407$. 
Singh RI, XessI, Mathur P, Behera B, Gupta B, Misra MC. Epidemiology of candidemia in critically ill trauma patients: Experiences of a level I trauma centre in North India. J. Med Microbiol 2011; 60: 342-8.

Tak V, Mathur P, Varghese P, Gunjiyal J, Xess I, Misra MC. The epidemiological profile of Candidemia at an Indian Trauma care centre. J Lab Physicians 2014; 6: 96-101.

Trick WE, Fridkin SK, Edwards JR, Hajjeh RA, Gaynes RP. Secular trends of hospital-acquired candidemia among intensive care unit patients in the United States during 1989-1999. Clin Infect Dis 2002; 35:627-630.
Verma AK, Prasad KN, Singh M, Dixit AK, Ayyagari A. Candidaemia in patients of a tertiary health care hospital from north India. Indian J Med Res 2003; 117:122128.

Wisplinghoff $\mathrm{H}$, Bischoff $\mathrm{T}$, Tallent SM, Seifert H, Wenzel RP, Edmond MB. Nosocomial bloodstream infections in US Hospitals. Analysis of 24, 179 cases from a prospective nationwide surveillance study. Clin Infect Dis 2004: 39: 309-17.

Xess I, Jain N, Hasan F, Mandal P, Banerjee U. Epidemiology of candidemia in a tertiary care centre of North India: 5year study. Infection 2007; 35:256-259.

\section{How to cite this article:}

Pallavi S. Tatte and Pramod R. Bhise. 2018. Antifungal Susceptibility Profile of Candida Isolates from Bloodstream Infections in Hospitalised Patients at Tertiary Care Hospital. Int.J.Curr.Microbiol.App.Sci. 7(10): 997-1009. doi: https://doi.org/10.20546/ijcmas.2018.710.111 